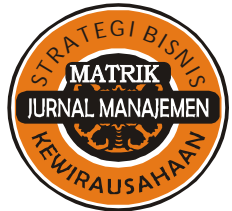

P-ISSN : 1978-2853 E-ISSN : 2302-8890

\section{MATRIK: JURNAL MANAJEMEN, STRATEGI BISNIS DAN KEWIRAUSAHAAN}

Homepage: https://ojs.unud.ac.id/index.php/jmbk/index

Vol. 14 No. 1, Februari 2020, 94-106

\title{
Pengaruh Family Supportive Supervisor Behavior terhadap Kepuasan Kerja melalui Work Life Balance dan Employee Engagement
}

\author{
Jundah Ayu Permatasari ${ }^{1)}$, Umar Nimran ${ }^{2)}$, Tri Wulida Afrianty ${ }^{3)}$ \\ ${ }^{1,2,3}$ Fakultas Ilmu Administrasi, Universitas Brawijaya, Malang \\ email: jundahayu@gmail.com
}

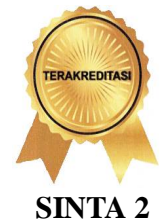

DOI : https://doi.org/10.24843/MATRIK:JMBK.2020.v14.i01.p10

\begin{abstract}
ABSTRAK
Penelitian ini dilatar belakangi oleh banyakya penelitian mengenai Work Life Balance pada konteks western country namun masih minimnya penelitian pada konteks eastern country. Penelitian ini bertujuan untuk menjelaskan pengaruh family supportive supervisor behavior (FSSB) terhadap work life balance (WLB), employee engagement dan kepuasan kerja pada perawat yang berstatus telah berkeluarga dan menjalani pekerjaan dengan sistem shift. Penelitian ini melibatkan 101 perawat RSUD Dr. Saiful Anwar Malang yang berada pada instalasi rawat inap (IRNA 1 dan IRNA 2) untuk menanggapi kuesioner. Teknik analisis data yang digunakan dalam penelitian ini adalah analisis statistik deskriptif dan teknik analisis jalur (path analysis). Temuan dalam penelitian ini menunjukkan bahwa FSSB tidak berpengaruh signifikan terhadap WLB, namun FSSB berpengaruh signifikan terhadap employee engagement dan kepuasan kerja. Hasil penelitian juga menunjukkan adanya perbedaan hasil penelitian pada konteks eastern country dengan penelitian terdahulu yang dilakukan pada konteks western country.
\end{abstract}

Kata kunci: Family supportive supervisor behavior, work life balance, employee engagement, kepuasan kerja

Family Supportive Supervisor Behavior, Job Satisfaction, Work Life Balance And Employee Engagement

\section{ABSTRACT}

Many studies on the Work Life Balance were carried out in western countries but there was still a lack of research in eastern countries. This study aims to explain the influence of family supportive supervisor behavior (FSSB) on work life balance (WLB), employee engagement and job satisfaction. This study involved married nurse and nurse who work with shift system. 101 nurses in RSUD Dr. Saiful Anwar Malang which stationed in inpatient facility (IRNA 1 and IRNA 2) were participated in the research. Data analysis technique used in this study was descriptive statistical analysis and path analysis technique. The findings of this study indicates that FSSB has no significant effect toward WLB, but it has significant effect on employee engagement and job satisfaction. The results of the study also showed differences in the results of the study in the eastern country context with previous studies conducted in the context of western country.

Keyword: Family supportive supervisor behavior, work life balance, employee engagement, job satisfaction

\section{PENDAHULUAN}

Pembahasan mengenai work life balance (WLB) telah menjadi topik yang sangat penting untuk dibicarakan dan diteliti oleh ilmuwan dan organisasi (Baral dan Bhargava, 2010). WLB adalah hal yang penting bagi karyawan agar karyawan dapat memiliki keseimbangan yang baik antara kehidupan pekerjaan dan kehidupan pribadinya (Baral dan Bhargava, 2010). Penelitian terdahulu menunjukkan bahwa karyawan yang merasa nyaman dengan pekerjaan mereka serta memiliki WLB yang efektif akan merasa bangga bekerja untuk organisasi mereka, hasil penelitian ini juga menunjukkan bahwa hal tersebut dapat meningkatkan kepuasaan kerja karyawan (Mas-Machuca, et al., 2016).

Pendekatan lain yang dapat dilakukan organisasi agar karyawan merasa nyaman dengan pekerjaannya sehingga dapat meningkatkan kinerja serta kepuasan kerja karyawan yaitu dengan mendorong karyawan untuk terikat dengan organisasinya. Employee engangement adalah pemikiran positif, memuaskan terkait dengan pekerjaan yang ditandai oleh vigor (semangat), dedication (dedikasi) dan absorption (absorpsi) 
(Schaufeli, et al., 2002). Penting bagi organisasi untuk membentuk karyawan yang memiliki rasa keterikatan dengan organisasi agar dapat melibatkan karyawan untuk kesuksesan tujuan organisasi. Organisasi harus menyadari kewajiban mereka dengan memastikan karyawan tidak bekerja terlalu keras sehingga mengganggu kehidupan di luar pekerjaan atau meningkatnya masalah kesehatan dan stres kerja yang dapat berdampak pada menurunnya moral karyawan, rendahnya produktivitas dan berkurangnya kepuasan kerja.

Kepuasan kerja adalah salah satu outcome organisasi yang banyak diteliti dan sangat penting untuk diperhatikan karena kepuasan kerja berdampak pada kinerja karyawan (Robbins dan Judge, 2013). Pekerjaan tidak hanya sekedar melakukan pekerjaan, tetapi juga terkait dengan aspek lain seperti interaksi dengan rekan sekerja, atasan, mengikuti aturan-aturan, dan lingkungan kerja tertentu yang sering kali tidak memadai atau kurang disukai (Robbins dan Judge, 2013).

Meningkatkan WLB, employee engangement serta kepuasan kerja tidak terlepas dari peran supervisor dalam organisasi itu sendiri. Bentuk dukungan supervisor yang spesifik terkait dengan dukungan supervisor terhadap peran karyawan di dalam keluarga disebut family supportive supervisor behavior (FSSB). FSSB adalah perilaku suportif dari supervisor terhadap keadaan keluarga bawahannya yang dapat membentuk persepsi bawahannya mengenai dukungan organisasi (Hammer, et al., 2007).

Beberapa jenis pekerjaan di Indonesia dijalankan secara terus menerus dalam waktu 24 jam. Sebagaimana tertuang dalam Kepmenakertrans No.233/Men/2003 pasal 1 (Republik Indonesia, 2013), yang dimaksud dengan pekerjaan yang dijalankan secara terus menerus adalah pekerjaan yang menurut jenis dan sifatnya harus dilaksanakan atau dijalankan secara terus menerus atau dalam keadaan lain berdasarkan kesepakatan antara pekerja/buruh dengan pengusaha. Pekerjaan yang jenis dan sifatnya harus dilakukan terus menerus adalah pekerjaan di bidang jasa kesehatan, pariwisata, transportasi, pos dan telekomunikasi, penyediaan listrik, pusat perbelanjaan, media massa, pengamanan dan lain lain yang diatur dalam Kepmenakertrans No.233/Men/2003 pasal 2 (Republik Indonesia, 2013). Penelitian ini mengambil lokasi penelitian yang beroprasi selama 24 jam yaitu rumah sakit.
Rumah sakit merupakan institusi yang menawarkan jasa pelayanan dengan menempatkan peran dari sumber daya manusia sebagai faktor yang penting. Perawat merupakan sumber daya manusia di dalam rumah sakit yang paling banyak berinteraksi dengan pasien. Dilansir dari majalah online mengenai kesehatan dengan judul artikel Careers With High Rates of Depression (Worth, 2011) petugas kesehatan termasuk dokter, perawat dan terapis memiliki jam kerja yang panjang dan tidak teratur serta rentan mengalami depresi. Penelitian ini dilakukan di RSUD Dr. Saiful Anwar Malang. RSUD Dr. Saiful Anwar Malang adalah rumah sakit Tipe A dan telah ditetapkan sebagai rumah sakit rujukan serta ditetapkan sebagai unsur penunjang pemerintah Provinsi setingkat dengan Badan. Berdasarkan hal tersebut kemungkinan workload perawat sangat tinggi sehingga dapat mengganggu WLB perawat.

Penelitian ini juga dilatar belakangi karena sebagian besar penelitian mengenai WLB berasal dari western country seperti Amerika Serikat, Inggris dan Kanada, sehingga literatur di lapangan didominasi oleh perspektif Barat (Hassan, et al., 2010). Indonesia memiliki perbedaan budaya dengan western country, dimana Indonesia adalah negara dengan budaya kolektivis (Afrianty, 2013). Berdasarkan pendapat-pendapat tersebut, penelitian ini ingin melihat bagaimana praktik WLB pada konteks eastern country khususnya Indonesia.

Selain itu, penelitian ini juga dilatar belakangi oleh research gap berdasarkan pada measurement yang digunakan pada penelitian. Beberapa penelitian mengukur supervisor support secara general (e.g., Baral dan Bhargava, 2010; Casper, et al., 2011; Mas-Machuca et al., 2016). Penelitian ini menggunakan pengukuran dari Hammer, et.al. (2011) dimana lebih berfokus kepada perhatian supervisor dibidang WLB. Oleh karena itu, instrumen yang digunakan adalah supervisor support yang lebih spesifik terkait dengan work family balance yang disebut dengan Family Supportive Supervisor Behavior (FSSB).

Penelitian ini juga berfokus pada perawat yang menjalani pekerjaan dengan sistem shift. Salah satu strategi untuk menumbuhkan WLB adalah dengan kerja paruh waktu, menyediakan lebih banyak kerja paruh waktu dengan jam atau shift yang lebih sedikit atau penyusunan pembagian kerja untuk seluruh karyawan. Walaupun sistem shift ini dibuat sebagai strategi untuk menumbuhkan WLB, namun beberapa 
penelitian di bidang kerja shift menunjukkan terdapat masalah-masalah dalam sistem kerja shift terkait dengan WLB (e.g., Bohle dan Tilley, 1998; Koller, 2004). Sistem shift dapat mempengaruhi kehidupan rumah tangga atau keluarga pada pekerja shift (Colquhoun, 1981) . Masalah yang disebabkan oleh sistem shift (seperti kelelahan, masalah kesehatan, dan ketidakpuasan kerja) bervariasi dalam waktu serta intensitas dan signifikan tidak hanya di negaranegara berkembang tetapi juga di negara-negara barat atau negara maju (Koller, 2004). Jadwal kerja shift mengakibatkan karyawan kesulitan dalam membagi waktu untuk menjalankan dua peran sekaligus baik di dalam pekerjaan maupun dikeluarga sehingga hal ini dapat mengganggu work life balance karyawan.

Hubungan antara FSSB dan WLB dapat dikaitkan dengan border theory (Clark, 2000). Border theory menjelaskan bagaimana individu mengatur dan menegosiasikan bidang antara pekerjaan dan kehidupan di luar pekerjaan, dan batasan antara keduanya untuk mencapai keseimbangan dan meminimalisir konflik. Konsep border theory menyatakan terdapat dua domain berbeda antara kehidupan di luar pekerjaan dan pekerjaan, sehingga seseorang harus melakukannya dalam aturan yang berbeda, baik dalam pola maupun perilakunya. Salah satu konsep border theory adalah border keeper, yaitu beberapa anggota dari ranah yang khususnya berpengaruh dalam mendefinisikan ranah dan border (batas). Border keeper di dalam suatu pekerjaan adalah supervisor (Handayani, 2013). Supervisor berperan sangat penting untuk membantu karyawan dalam mencapai WLB. Penelitian oleh Mas-Machuca et al. (2016) menemukan bahwa supervisor yang mendukung WLB berpengaruh positif terhadap employee work life balance. (Mas-Machuca et al. (2016) menyatakan, jika supervisor percaya dan mendukung semua komponen work life initiatives maka hal tersebut akan membuat karyawan lebih mudah untuk mecapai WLB pada level yang tinggi. Berdasarkan tinjauan teoritis dan empiris tersebut, maka hipotesis yang dikembangkan dalam penelitian ini adalah:

$\mathrm{H}_{1}$ : FSSB berpengaruh signifikan terhadap WLB perawat.

Teori yang mendukung hubungan antara FSSB dengan employee engagement adalah social exchange theory yang dikemukakan oleh Thibault dan Kelley. Social exchange theory melihat antara perilaku dengan lingkungan terdapat hubungan yang saling mempengaruhi (reciprocal). Ketika seseorang memperlakukan orang lain dengan baik, hukum timbal balik (reciprocity norm) mewajibkan mereka untuk melakukan hal yang sama (Rhoades dan Eisenberger, 2002). Employee engagement adalah keterlibatan karyawan dan rasa keterikatan di dalam organisasi dimana karyawan mendedikasikan dirinya untuk kesuksesan tujuan organisasi. FSSB dapat mendorong timbulnya employee engagement. Berdasarkan social exchange theory, karyawan akan memberikan kontribusi sesuai dengan apa yang mereka dapatkan, dalam hal ini adalah FSSB. Sehingga dapat disimpulkan jika mengacu pada social exchange theory, karyawan akan memiliki employee engagement yang tinggi sebagai dampak dari perlakuan baik dan perhatian dari supervisor mereka. Penelitian terdahulu menemukan bahwa supervisor harus menunjukan pentingnya engagement pada sektor publik di Uni Emirat Arab (UAE) karena akan meningkatkan kinerja karyawan, meningkatkan kepuasan kerja sehingga dapat membantu organisasi untuk mencapai tujuan (Ibrahim dan Al Falasi, 2014). Berdasarkan pendapat tersebut maka dapat dikatakan bahwa bawahan melihat supervisor support sebagai perpanjangan pribadi organisasi (Eisenberger et al., 1986). Hasil penelitian lain yang mendukung hubungan antar variabel ini adalah penelitian oleh Abigail dan Johnson (2014) yang menemukan adanya hubungan langsung yang signifikan antara FSSB dengan employee engagement. Berdasarkan tinjauan teoritis dan empiris tersebut, maka hipotesis yang dikembangkan dalam penelitian ini adalah:

$\mathrm{H}_{2}$ : FSSB berpengaruh signifikan terhadap Employee Engagement perawat.

Hubungan FSSB dengan kepuasan kerja dapat dikaitkan dengan organizational support theory (Eisenberger, et al., 1986). Organizational support theory menyatakan bahwa untuk menentukan kesiapan organisasi untuk menghargai peningkatan usaha kerja dan untuk memenuhi kebutuhan sosioemosional, karyawan mengembangkan kepercayaan mengenai sejauh mana organisasi menghargai kontribusi dan kepedulian mereka terhadap kesejahteraan mereka. Karena supervisor adalah agen organisasi, penerimaan karyawan atas perlakuan baik dari supervisor memiliki kontribusi 
terhadap Perceived Organizational Support (POS). (Munn, et al., 1996) menemukan bahwa supervisor support adalah prediktor terbaik dari kepuasan kerja dan turnover intention. Karyawan yang merasa supervisor mereka mendukung WLB ditemukan memiliki kepuasan kerja dan komitmen yang lebih tinggi (Aryee, et al., 2005). Berdasarkan tinjauan teoritis dan empiris tersebut, maka hipotesis yang dikembangkan dalam penelitian ini adalah:

$\mathrm{H}_{3}$ : FSSB berpengaruh signifikan terhadap Kepuasan Kerja perawat.

WLB dalam arti luas adalah tingkat kepuasan dari keterlibatan atau kesesuaian antara peran ganda dalam kehidupan seseorang (Hudson, 2005). Hubungan antara WLB dan kepuasan kerja dapat dikaitkan dengan border theory (Clark, 2000). Border theory menjelaskan bagaimana individu mengatur dan menegosiasikan bidang antara pekerjaan dan kehidupan di luar pekerjaan, dan batasan antara keduanya untuk mencapai keseimbangan dan meminimalisir konflik. Konsep border theory menyatakan terdapat dua domain berbeda antara kehidupan di luar pekerjaan dan pekerjaan, sehingga seseorang harus melakukannya dalam aturan yang berbeda, baik dalam pola maupun perilakunya, misalnya pekerjaan bisa dirasakan puas oleh seseorang ketika mereka memiliki prestasi yang baik dan mendapatkan pemasukan, sedangkan kepuasan di luar pekerjaan didapat jika mencapai hubungan yang sangat dekat dengan keluarga, teman, dan kerabat lainnya. Penelitian telah menunjukkan bahwa WLB berpengaruh positif terhadap kepuasan kerja (Haar, et al., 2014; Mas-Machuca et al., 2016). Tingkat tingginya WLB lebih berhubungan secara positif dengan kepuasan kerja pada berbagai macam budaya dan budaya sebagai variabel moderating pada hubungan ini (Haar et al., 2014). Berdasarkan tinjauan teoritis dan empiris tersebut, maka hipotesis yang dikembangkan dalam penelitian ini adalah:

$\mathrm{H}_{4}$ : WLB berpengaruh signifikan terhadap Kepuasan Kerja perawat.

Hubungan employee engagement dengan kepuasan kerja dapat dikaitkan dengan job demand and job resources theory (JDR theory). JDR theory menetapkan bahwa terdapat dua jenis elemen yang berbeda dalam pekerjaan yaitu, job demand dan job resource (Bakker dan Demerouti, 2007). Job demand adalah karakteristik dari organisasi, yang memerlukan upaya karyawan. Upaya ini dikaitkan dengan biaya fisik dan psikologis (mental atau emosional). Di sisi lain, job resource adalah karakteristik pekerjaan (fisik, psikologis, sosial, dan organisasi) yang memungkinkan untuk menangani job demand. Job resource terkait erat dengan employee engagement (Ramos dan Almeida, 2017). Employee engagement terkait dengan sikap pekerjaan, seperti kepuasan kerja dan komitmen organisasi (Crawford, et al., 2010). Karyawan yang engaged merasa bahwa pekerjaan yang mereka lakukan memiliki arti dan makna. Mereka menunjukkan kinerja yang lebih baik dalam tugas, menilai secara positif pekerjaan yang mereka lakukan dan mengalami tingkat kepuasan yang lebih besar. Sejalan dengan pendapat tersebut, kepuasan kerja merupakan salah satu consequences dari employee engagement (Saks, 2005). Berdasarkan tinjauan teoritis dan empiris tersebut, maka hipotesis yang dikembangkan dalam penelitian ini adalah:

$\mathrm{H}_{5}$ : Employee Engagement berpengaruh signifikan terhadap Kepuasan Kerja perawat.

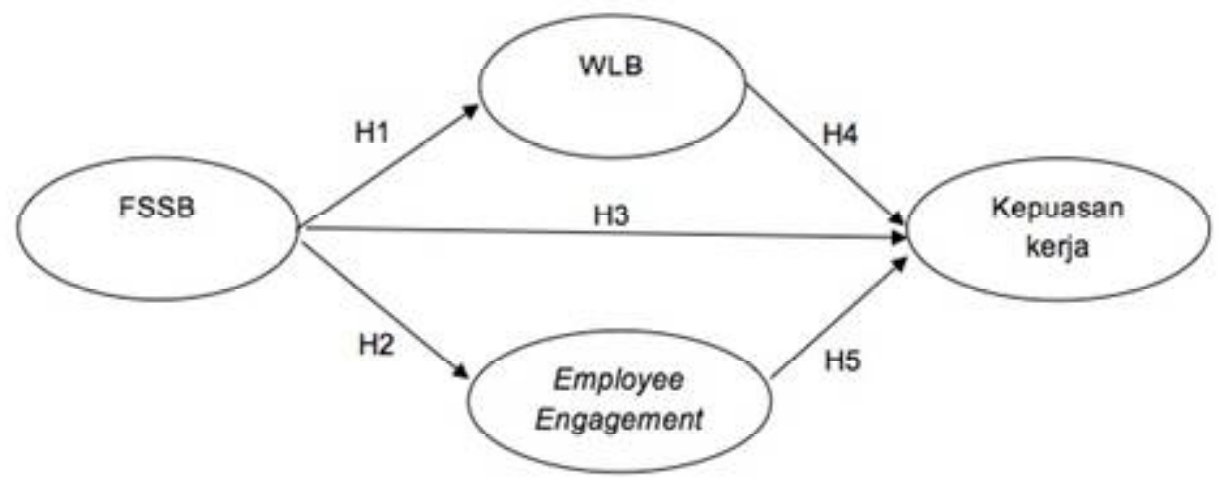

Gambar 1. Kerangka Konseptual Penelitian 


\section{METODE PENELITIAN}

Jenis penelitian yang digunakan dalam penelitian ini adalah jenis penelitian explanatory research dengan pendekatan kuantitatif. Teknik analisis data yang digunakan dalam penelitian ini adalah analisis statistik deskriptif dan teknik analisis jalur (path analysis) menggunakan SPSS 16.0. Penelitian ini dilakukan di RSUD Dr. Saiful Anwar Malang, khususnya instalasi rawat inap (IRNA 1 dan IRNA 2). Total populasi dalam penelitian ini sebanyak 136 perawat dengan status telah berkeluarga dan bekerja dengan sistem shift. Pengambilan sampel ini dilakukan dengan cara proportional cluster sampling. Penentuan jumlah sampel dalam penelitian ini menggunakan rumus slovin dengan tingkat kesalahan sebesar 5\% sehingga sampel yang didapatkan berjumlah 101 perawat. Instrumen penelitian menggunakan kuesioner dan skala pengukuran menggunakan skala Likert.

Tabel 1. Definisi Operasional Variabel

\begin{tabular}{|c|c|c|c|}
\hline VARIABEL & DEFINISI & & INDIKATOR \\
\hline $\begin{array}{c}\text { FSSB } \\
(\mathrm{X}) \\
\text { (Hammer et al., 2011) }\end{array}$ & $\begin{array}{l}\text { FSSB adalah perilaku } \\
\text { supervisor yang memberikan } \\
\text { dukungan serta empati } \\
\text { terhadap bawahan mereka } \\
\text { terkait dengan keseimbangan } \\
\text { antara tanggung jawab di } \\
\text { dalam pekerjaan dan keluarga } \\
\text { sehingga dapat membentuk } \\
\text { persepsi bawahan mengenai } \\
\text { dukungan organisasi. }\end{array}$ & $\begin{array}{l}\text { 1) } \\
\text { 2) } \\
\text { 3) }\end{array}$ & $\begin{array}{l}\text { Emotional Support } \\
\text { Instrumental Support } \\
\text { Role Modeling } \\
\text { Behaviour } \\
\text { Creative Work } \\
\text { Family Management }\end{array}$ \\
\hline $\begin{array}{c}\text { WLB } \\
(\mathrm{Z} 1) \\
\text { (Hayman, 2005) }\end{array}$ & $\begin{array}{l}\text { WLB adalah keadaan dimana } \\
\text { individu dapat } \\
\text { menyeimbangkan perannya } \\
\text { baik di dalam pekerjaan } \\
\text { maupun peran di luar } \\
\text { pekerjaan seperti kehidupan } \\
\text { pribadi, keluarga, spiritual, } \\
\text { dan sosial. }\end{array}$ & 1) & $\begin{array}{lr}\text { Work Interference } \\
\text { with Personal } & \text { Life } \\
\text { (WIPL) } & \\
\text { Personal } & \text { Life } \\
\text { Interference } & \text { with } \\
\text { Work (PLIW) } & \\
\text { Work/personal } & \\
\text { Enhanchement } & \text { of } \\
\text { Personal } & \text { Life } \\
\text { (WPLE) } & \end{array}$ \\
\hline $\begin{array}{l}\text { Employee engagement } \\
\text { (Z2) } \\
\text { (Schaufeli et al., 2002) }\end{array}$ & $\begin{array}{l}\text { Employee engagement adalah } \\
\text { keterlibatan karyawan dan } \\
\text { rasa keterikatan di dalam } \\
\text { organisasi dimana karyawan } \\
\text { mendedikasikan dirinya untuk } \\
\text { kesuksesan tujuan organisasi. }\end{array}$ & $\begin{array}{l}\text { 1) } \\
\text { 2) } \\
\text { 3) }\end{array}$ & $\begin{array}{l}\text { Vigor } \\
\text { Dedication } \\
\text { Absorption }\end{array}$ \\
\hline $\begin{array}{c}\text { Kepuasan Kerja } \\
(\mathrm{Y}) \\
\text { (Closon, Leys, \& Hellemans, } \\
\text { 2015) }\end{array}$ & $\begin{array}{lrr}\text { Kepuasan kerja adalah } \\
\text { keadaan emosional yang } \\
\text { menyenangkan atau tidak } \\
\text { menyenangkan bagi para } \\
\text { karyawan dalam memandang } \\
\text { pekerjaan mereka. }\end{array}$ & $\begin{array}{l}\text { 1) } \\
\text { 2) } \\
\text { 3) } \\
\text { 4) }\end{array}$ & $\begin{array}{l}\text { Gaji } \\
\text { Pekerjaan itu sendiri } \\
\text { Lingkungan kerja } \\
\text { Hubungan kerja } \\
\text { dengan rekan kerja } \\
\text { Supervisi }\end{array}$ \\
\hline
\end{tabular}

Sumber : Data diolah, 2018

Variabel independen dalam penelitian ini adalah FSSB (X). Variabel intervening dalam penelitian ini adalah WLB (Z1) dan Employee Engagement (Z2). Variabel dependen dalam penelitian ini adalah Kepuasan Kerja (Y).

\section{HASIL DAN PEMBAHASAN}

Penelitian ini menggunakan uji validitas dan reliabilitas untuk menguji kevalidan dan kehandalan dari instrumen penelitian yang digunakan. Tabel 2 merupakan hasil uji validitas variabel. Pada variabel $\mathrm{Z} 1$, terdapat item Z1.7, Z1.14, dan Z1.15 yang memiliki nilai $r$ hitung dibawah 0,196 sehingga item tersebut harus dikeluarkan (tidak digunakan sebagai item pernyataan dalam kuesioner terkait variabel Kepuasan kerja). Pada variabel Y, terdapat item Y2 yang memiliki nilai $r$ hitung dibawah 0,196 sehingga item tersebut juga harus dikeluarkan. Pada 
itemZ1.1,Z1.2, Z1.3, Z1.4, Z1.5, Z1.6,Z1.8, Z1.9, $\mathrm{Z} 1.10, \mathrm{Z} 1.11, \mathrm{Y} 2$ dan $\mathrm{Y} 3$ juga telah dilakukan reverse code atau reverse score yaitu membalik pemberian skor karena item pernyataan ditulis dengan kalimat negatif. Item yang tidak valid dikeluarkan dilakukan pengujian ulang. Adapun hasil uji validitas variabel setelah dilakukan pengujian adalah sebagai berikut :

Tabel 2. Hasil Uji Validitas Variabel

\begin{tabular}{|c|c|c|c|c|}
\hline Variabel & Item & r hitung & r Tabel & Keterangan \\
\hline \multirow{14}{*}{$\operatorname{FSSB}(\mathrm{X})$} & X.1 & 0.790 & 0.196 & Valid \\
\hline & X.2 & 0.738 & 0.196 & Valid \\
\hline & X.3 & 0.775 & 0.196 & Valid \\
\hline & X.4 & 0.790 & 0.196 & Valid \\
\hline & X.5 & 0.667 & 0.196 & Valid \\
\hline & X.6 & 0.811 & 0.196 & Valid \\
\hline & X.7 & 0.875 & 0.196 & Valid \\
\hline & X.8 & 0.811 & 0.196 & Valid \\
\hline & X.9 & 0.844 & 0.196 & Valid \\
\hline & X.10 & 0.861 & 0.196 & Valid \\
\hline & X.11 & 0.774 & 0.196 & Valid \\
\hline & X.12 & 0.793 & 0.196 & Valid \\
\hline & X.13 & 0.797 & 0.196 & Valid \\
\hline & X.14 & 0.831 & 0.196 & Valid \\
\hline \multirow{12}{*}{ WLB (Z1) } & Z1.1 & 0.746 & 0.196 & Valid \\
\hline & $\mathrm{Z} 1.2$ & 0.731 & 0.196 & Valid \\
\hline & Z1.3 & 0.625 & 0.196 & Valid \\
\hline & Z1.4 & 0.430 & 0.196 & Valid \\
\hline & Z1.5 & 0.720 & 0.196 & Valid \\
\hline & Z1.6 & 0.378 & 0.196 & Valid \\
\hline & Z1.8 & 0.557 & 0.196 & Valid \\
\hline & Z1.9 & 0.651 & 0.196 & Valid \\
\hline & Z1.10 & 0.669 & 0.196 & Valid \\
\hline & Z1.11 & 0.657 & 0.196 & Valid \\
\hline & Z1.12 & 0.261 & 0.196 & Valid \\
\hline & Z1.13 & 0.287 & 0.196 & Valid \\
\hline \multirow{17}{*}{$\begin{array}{c}\text { Employee } \\
\text { Engagement } \\
\text { (Z2) }\end{array}$} & $\mathrm{Z} 2.1$ & 0.645 & 0.196 & Valid \\
\hline & $\mathrm{Z} 2.2$ & 0.789 & 0.196 & Valid \\
\hline & $\mathrm{Z} 2.3$ & 0.469 & 0.196 & Valid \\
\hline & Z2.4 & 0.385 & 0.196 & Valid \\
\hline & $\mathrm{Z} 2.5$ & 0.541 & 0.196 & Valid \\
\hline & $\mathrm{Z} 2.6$ & 0.676 & 0.196 & Valid \\
\hline & Z2.7 & 0.740 & 0.196 & Valid \\
\hline & $\mathrm{Z} 2.8$ & 0.805 & 0.196 & Valid \\
\hline & Z2.9 & 0.820 & 0.196 & Valid \\
\hline & $\mathrm{Z} 2.10$ & 0.676 & 0.196 & Valid \\
\hline & $\mathrm{Z} 2.11$ & 0.505 & 0.196 & Valid \\
\hline & $\mathrm{Z} 2.12$ & 0.667 & 0.196 & Valid \\
\hline & Z2.13 & 0.666 & 0.196 & Valid \\
\hline & $\mathrm{Z} 2.14$ & 0.369 & 0.196 & Valid \\
\hline & Z2.15 & 0.331 & 0.196 & Valid \\
\hline & Z2.16 & 0.419 & 0.196 & Valid \\
\hline & Z2.17 & 0.675 & 0.196 & Valid \\
\hline \multirow{10}{*}{$\begin{array}{c}\text { Kepuasan Kerja } \\
\text { (Y) }\end{array}$} & Y.1 & 0.722 & 0.196 & Valid \\
\hline & Y.3 & 0.416 & 0.196 & Valid \\
\hline & Y.4 & 0.610 & 0.196 & Valid \\
\hline & Y.5 & 0.705 & 0.196 & Valid \\
\hline & Y.6 & 0.702 & 0.196 & Valid \\
\hline & Y.7 & 0.631 & 0.196 & Valid \\
\hline & Y.8 & 0.863 & 0.196 & Valid \\
\hline & Y.9 & 0.493 & 0.196 & Valid \\
\hline & Y.10 & 0.518 & 0.196 & Valid \\
\hline & Y.11 & 0.693 & 0.196 & Valid \\
\hline
\end{tabular}


100 Matrik: Jurnal Manajemen, Strategi Bisnis dan Kewirausahaan Vol. 14, No. 1, Februari 2020

Tabel 3. Hasil Uji Realibilitas Variabel

\begin{tabular}{lll}
\hline \multicolumn{1}{c}{ Variabel } & \multicolumn{1}{c}{ Koefisien Alpha } & \multicolumn{1}{c}{ Keterangan } \\
\hline FSSB (X) & 0.955 & Reliabel \\
WLB (Z1) & 0.826 & Reliabel \\
Employee engagement (Z2) & 0.876 & Reliabel \\
Kepuasan kerja (Y) & 0.828 & Reliabel \\
\hline
\end{tabular}

Sumber : Data primer diolah, 2018

Hasil uji reliabilitas variabel penelitian dapat dilihat pada Tabel 3. Dari Tabel 3 dapat diketahui bahwa nilai dari alpha cronbach untuk semua variabel lebih besar dari 0,6 sehingga dapat dikatakan item pernyataan yang digunakan dalam penelitian ini sudah reliabel.

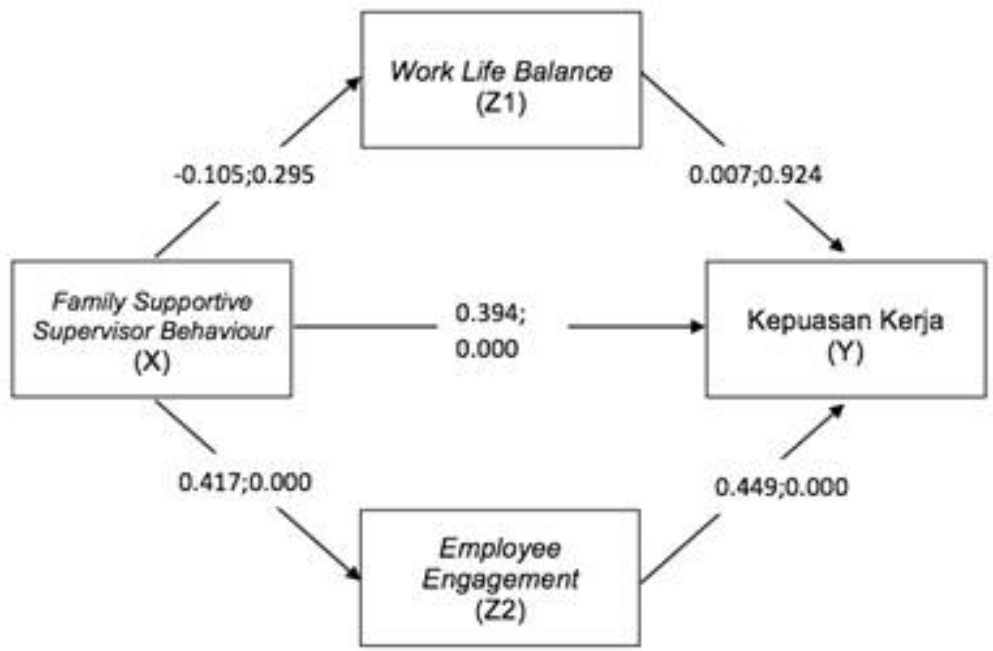

Sumber: Data primer diolah, 2018

Gambar 2. Diagram Hasil Analisis Jalur

Tabel 4. Rekapitulasi Hasil Analisis Jalur (Path Analysis)

\begin{tabular}{ccccc}
\hline $\begin{array}{c}\text { Hubungan } \\
\text { Variabel }\end{array}$ & Coefficients & t hitung & p-value & Keterangan \\
\hline X - Z1 & -0.105 & -1.054 & 0.295 & Tidak Signifikan \\
X - Z2 & 0.417 & 4.568 & 0.000 & Signifikan \\
X - Y & 0.394 & 4.997 & 0.000 & Signifikan \\
Z1 - Y & 0.007 & 0.095 & 0.924 & Tidak Signifikan \\
Z2 - Y & 0.449 & 5.691 & 0.000 & Signifikan \\
\hline
\end{tabular}

Sumber : Data primer diolah, 2018

Hasil yang diperoleh pada pengujian hipotesis pertama (H1) menunjukkan bahwa pengaruh variabel FSSB $(\mathrm{X})$ terhadap WLB $(\mathrm{Z1})$ memiliki nilai koefisien sebesar -0,105 dengan nilai t sebesar 1,054 dan $p$-value sebesar 0,295. Hasil tersebut menunjukkan bahwa variabel FSSB berpengaruh tidak signifikan terhadap WLB, sehingga tidak mendukung hipotesis pertama yaitu FSSB (X) berpengaruh signifikan terhadap WLB (Z1).

Dukungan yang diterima karyawan dari organisasi mungkin dibayangi oleh dukungan keluarga karyawan (family support) (Afrianty, 2013). Menurut border theory yang dikemukakan, salah satu konsep adalah border keeper, yaitu beberapa anggota dari ranah yang khususnya berpengaruh dalam mendefinisikan ranah dan border (batas). Border keeper di tempat kerja yang dapat membantu dalam mendefinisikan ranah adalah supervisor sedangkan boder keeper dalam kehidupan sehari-hari adalah pasangan dan anggota keluarga lainnya (extended family). Border keeper memiliki peran yang penting dalam kemampuan seseorang untuk mengatur domain dan batas (Clark, 2000).

Anggota keluarga memiliki kontribusi unik dalam emotional dan instrumental support bagi 
karyawan diluar lingkungan pekerjaannya (Brough, O'Driscoll, dan Kalliath, 2005). Menurut (Afrianty, 2013), kebanyakan keluarga di Indonesia tinggal bersama dengan orang tua atau mertua atau bahkan dengan keluarga besar lainnya (extended family) memungkinkan karyawan yang sudah menikah untuk mengurangi beban pekerjaan rumah tangga melalui bantuan orang-orang yang tinggal bersama mereka. Penelitian pada konteks Indonesia yang dilakukan di RSUD Dr. Saiful Anwar Malang belum dapat mendukung hipotesis. Hal ini dikarenakan mungkin perawat memiliki dukungan di rumah yang lebih tinggi (extended family) daripada dukungan di organisasi. Menurut (Afrianty, 2013), jenis family support ini adalah salah satu faktor yang dapat membentuk persepsi karyawan tentang pentingnya work life balance support yang disediakan oleh organisasi. Semakin banyak dukungan keluarga yang dimiliki karyawan, semakin besar kemungkinan mereka memberi nilai yang lebih rendah pada dukungan organisasi.

Hasil yang diperoleh pada pengujian hipotesis kedua (H2) menunjukkan bahwa pengaruh variabel FSSB (X) terhadap Employee Engagement (Z2) memiliki nilai koefisien sebesar 0,417 dengan nilai t sebesar 4,568 dan p-value sebesar 0,000. Hasil tersebut menunjukkan bahwa variabel FSSB memiliki pengaruh yang signifikan terhadap variabel Employee Engagement, sehingga mendukung hipotesis kedua yaitu FSSB (X) berpengaruh signifikan terhadap employee engagement (Z2).

Temuan dalam penelitian ini menunjukkan bahwa FSSB dapat mendorong timbulnya employee engagement pada perawat RSUD Dr. Saiful Anwar. Berdasarkan social exchange theory, karyawan akan memberikan kontribusi sesuai dengan apa yang mereka dapatkan, dalam hal ini adalah FSSB. Temuan dalam penelitian ini menunjukkan bahwa perawat pada RSUD Dr. Saiful Anwar Malang memiliki employee engagement yang baik dengan nilai mean yang cukup tinggi yaitu 3,81 dimana sebagian besar responden menjawab "setuju" pada semua item pernyataan pada variable employee engagement. Temuan ini menunjukkan employee engagement yang baik terbentuk sebagai dampak dari perlakuan baik dan perhatian dari supervisor mereka. Sehingga temuan dalam penelitian ini sesuai dengan social exchange theory. Temuan dalam penelitian ini membuktikan bahwa FSSB dapat mendorong timbulnya employee engagement, sehingga RSUD Dr. Saiful Anwar Malang memerlukan supervisor yang support agar dapat menciptakan employee engagement pada perawatnya.

Hasil penelitian ini memperkuat penelitian terdahulu yang menemukan bahwa supervisor menunjukan pentingnya engagement pada sektor publik di Uni Emirat Arab (UAE) karena akan meningkatkan kinerja karyawan, meningkatkan kepuasan kerja sehingga dapat membantu organisasi untuk mencapai tujuan (Ibrahim dan Al Falasi, 2014). Penelitian terdahulu juga menemukan adanya hubungan langsung yang signifikan antara FSSB dengan employee engagement (Abigail dan Johnson, 2014) .

Hasil yang diperoleh pada pengujian hipotesis ketiga (H3) menunjukkan bahwa pengaruh variabel FSSB (X) terhadap Kepuasan kerja (Y) memiliki nilai koefisien sebesar 0,394 dengan nilai t sebesar 4,997 dan p-value sebesar 0,000. Hasil tersebut menunjukkan bahwa variabel FSSB memiliki pengaruh yang signifikan terhadap variabel kepuasan kerja, sehingga mendukung hipotesis ketiga yaitu "FSSB (X) berpengaruh signifikan terhadap kepuasan kerja (Y)".

Temuan dalam penelitian ini mengindikasikan bahwa FSSB dapat menciptakan kepuasan kerja pada perawat RSUD Dr. Saiful Anwar. Hasil penelitian ini mendukung organizational support theory. Organizational support theory menyatakan bahwa untuk menentukan kesiapan organisasi untuk menghargai peningkatan usaha kerja dan untuk memenuhi kebutuhan sosioemosional, karyawan mengembangkan kepercayaan mengenai sejauh mana organisasi menghargai kontribusi dan kepedulian mereka terhadap kesejahteraan mereka (Eisenberger et al., 1986).

Berdasarkan temuan dalam penelitian ini maka supervisor sebagai agen dari RSUD Dr. Saiful Anwar dapat memberikan perlakuan baik sebagai supervisor yang support kepada para perawat sehingga dapat menciptakan kepuasan kerja. Hal tersebut sesuai dengan Organizational support theory yang juga membahas masalah proses psikologis yang mendasari konsekuensi Perceived Organizational Support (POS). Salah satunya, proses ini harus memiliki hasil yang baik untuk organisasi dan karyawan. Hasil yang di dapat untuk organisasi seperti peningkatan komitmen afektif dan kinerja serta pengurangan turnover. Hasil bagi karyawan adalah meningkatkan positive mood dan juga kepuasan kerja. Penelitian terdahulu juga 
menemukan bahwa supervisor support adalah prediktor terbaik dari kepuasan kerja dan turnover intention (e.g. (Aryee et al., 2005; Munn et al., 1996)

Hasil yang diperoleh pada pengujian hipotesis keempat (H4) menunjukkan bahwa pengaruh variabel WLB (Z1) terhadap Kepuasan kerja (Y) memiliki nilai koefisien sebesar 0,007 dengan nilai t sebesar 0,095 dan probabilitas sebesar 0,924. Hasil tersebut menunjukkan bahwa variabel WLB berpengaruh tidak signifikan terhadap kepuasan kerja, sehingga tidak mendukung hipotesis keempat.

Hasil penelitian ini tidak sejalan dengan pernyataan yang dikemukakan oleh Haar (2014) yang menunjukkan bahwa tingkat tingginya WLB lebih berhubungan secara signifikan dengan kapuasan kerja pada berbagai macam budaya dan budaya sebagai variabel moderating pada hubungan ini. Penelitian (Afrianty, 2013), menemukan bahwa pengalaman WLB di Indonesia tidak sejalan dengan temuan dalam penelitian serupa pada konteks western country, dimana WLB mengarah pada hasil kerja yang positif dan penurunan work family conflict.

Pada dasarnya kepuasan kerja merupakan hal yang bersifat individu karena setiap individu memiliki tingkat kepuasan yang berbeda sesuai dengan sistem nilai-nilai yang berlaku pada dirinya (Sutrisno, 2014). Beberapa individu mungkin akan merasa puas saat WLB nya terpenuhi, beberapa lagi mungkin akan puas dengan karier yang bagus, tapi ada beberapa juga yang puas dengan gaji yang mereka terima. Tingkat pendapatan dan kondisi keluarga karyawan dapat menentukan perilaku karyawan mengenai WLB (Choi, 2008). (Afrianty, 2013) menambahkan bahwa orang Indonesia percaya bahwa kerja keras adalah cara utama untuk mensejahterakan keluarga.

Afrianty, 2013 menyatakan dalam konteks Indonesia, pendapatan dari suatu pekerjaan adalah sumber keuangan yang utama dalam mendukung kehidupan keluarga, hilangnya sumber pendapatan dapat meningkatkan work family conflict karena akan berpengaruh kepada karyawan yang memiliki tanggungan (seperti anak-anak).
Hasil yang diperoleh pada pengujian hipotesis kelima (H5) menunjukkan bahwa pengaruh variabel employee engagement (Z2) terhadap Kepuasan kerja (Y) memiliki nilai koefisien sebesar 0.483 dengan nilai t sebesar 6.288 dan probabilitas sebesar 0.000 . Hasil tersebut menunjukkan bahwa variabel employee engagement (Z2) memiliki pengaruh yang signifikan terhadap variabel kepuasan kerja, sehingga mendukung hipotesis keempat yaitu employee engagement (Z2) berpengaruh signifikan terhadap Kepuasan kerja (Y).

Temuan dalam penelitian ini mengindikasikan bahwa employee engagement dapat menciptakan kepuasan kerja pada perawat RSUD Dr. Saiful Anwar. Hasil penelitian ini dapat dijelaskan dengan job demand and job resources theory (JDR theory). Job resource terkait erat dengan employee engagement, dan employee engagement terkait dengan sikap pekerjaan, seperti kepuasan kerja dan komitmen organisasi (Bakker dan Demerouti, 2007). Sejalan dengan teori tersebut, hasil penelitian ini menunjukkan bahwa perawat pada RSUD Dr. Saiful Anwar yang engaged merasa bahwa pekerjaan yang mereka lakukan memiliki arti dan makna. Mereka menunjukkan kinerja yang lebih baik dalam tugas, menilai secara positif pekerjaan yang mereka lakukan dan mengalami tingkat kepuasan kerja yang lebih besar.

Temuan dalam penelitian ini memperkuat beberapa penelitian terdahulu yang telah dilakukan sebelumnya yang menyatakan bahwa kepuasan kerja merupakan salah satu consequences dari employee engagement (Saks, 2005). Selanjutnya penelitian terdahulu menemukan bahwa karyawan yang engaged di tempat kerja akan lebih mungkin untuk merasakan kepuasan kerja (Yeh, 2013). Penelitian terdahulu juga menemukan bahwa ketiga dimensi dari employee engagement (vigor, dedication, absorption) memiliki hubungan yang positif dan signifikan terhadap kepuasan kerja (Allan, et al., 2016).

Tabel 5. Hasil Pengujian Pengaruh Tidak Langsung

\begin{tabular}{cccccccc}
\hline Variabel & \multicolumn{2}{c}{ Koefisien Langsung } & standar error & Koefisien TL & $\begin{array}{c}\text { Z } \\
\text { Hitung }\end{array}$ & p-value \\
\hline X, Z1, Y & -0.105 & 0.007 & 0.064 & 0.053 & -0.001 & -0.132 & 0,895 \\
X, Z2, Y & 0.417 & 0.449 & 0.064 & 0.052 & 0.187 & 5,201 & 0,000 \\
\hline
\end{tabular}

Sumber : Data primer diolah, 2018 
Berdasarkan Tabel 5 didapatkan bahwa pengaruh tidak langsung dari variabel FSSB terhadap kepuasan kerja melalui WLB sebesar -0,001. Hasil pengujian tersebut didapatkan nilai $Z$ hitung sebesar $-0,132$ dan $p$-value sebesar 0,895 . Nilai Z hitung $-0,132<1,96$ dan $p$-value $0,895>0,05$ hal ini berarti bahwa FSSB berpengaruh tidak signifikan terhadap kepuasan kerja melalui WLB. Hasil penelitian oleh MasMachuca et al. (2016) menemukan bahwa supervisor work life balance support berpengaruh positif terhadap employee work life balance. MasMachuca et al. (2016) menunjukkan bahwa karyawan yang merasa nyaman dengan pekerjaan mereka serta memiliki WLB yang efektif akan merasa bangga bekerja untuk organisasi mereka, hasil penelitian ini juga menunjukkan bahwa hal tersebut dapat meningkatkan kepuasaan kerja karyawan. Berdasarkan pendapat tersebut maka dapat disimpulkan bahwa WLB dapat berperan sebagai variabel mediasi antara FSSB dan kepuasan kerja. Namun, pada penelitian ini WLB mendapatkan nilai grandmean yang cukup rendah sehingga dapat disimpulkan bahwa WLB perawat pada RSUD Dr. Saiful Anwar Malang berada pada kategori tidak cukup baik. Hal tersebut menyebabkan FSSB memiliki pengaruh yang tidak signifikan terhadap kepuasan kerja melalui WLB. Menurut Afrianty (2013), kebanyakan keluarga di Indonesia tinggal bersama dengan orang tua atau mertua atau bahkan dengan keluarga besar lainnya (extended family) dan memungkinkan karyawan yang sudah menikah untuk mengurangi beban pekerjaan rumah tangga melalui bantuan orang-orang yang tinggal bersama mereka. Hal ini memungkinkan perawat memiliki dukungan di rumah yang lebih tinggi (extended family) daripada dukungan di organisasi. Selain itu, pada dasarnya kepuasan kerja merupakan hal yang bersifat individu karena setiap individu memiliki tingkat kepuasan yang berbeda sesuai dengan sistem nilai-nilai yang berlaku pada dirinya (Sutrisno, 2014). Beberapa individu mungkin akan merasa puas saat WLB nya terpenuhi, beberapa lagi mungkin akan puas dengan karier yang bagus, tapi ada beberapa juga yang puas dengan gaji yang mereka terima. Tingkat pendapatan dan kondisi keluarga karyawan dapat menentukan perilaku karyawan mengenai WLB (Choi, 2008). Afrianty (2013) menambahkan bahwa orang Indonesia percaya bahwa kerja keras adalah cara utama untuk mensejahterakan keluarga. Berdasarkan alasan-alasan tersebut maka dapat disimpulkan bahwa untuk saat ini, penelitian pada konteks Indonesia yang dilakukan di RSUD Dr. Saiful Anwar Malang belum dapat mendukung hipotesis.

Tabel 5 juga menunjukkan bahwa pengaruh tidak langsung dari variabel FSSB terhadap kepuasan kerja melalui Employee Engagement sebesar 0,187. Hasil pengujian tersebut didapatkan nilai $\mathrm{Z}$ hitung sebesar 5,201 dan p-value sebesar 0,000. Nilai Z hitung 5,201 > 1,96 dan $p$-value $0,000<0,05$ sehingga hal ini berarti bahwa FSSB berpengaruh signifikan terhadap kepuasan kerja melalui employee engagement. Dapat disimpulkan bahwa variabel employee engagement memiliki pengaruh yang paling tinggi dalam memediasi pengaruh FSSB terhadap kepuasan kerja. Menurut Robbins dan Judge (2013) faktor-faktor yang mempengaruhi employee engagement salah satunya yaitu organisasi memiliki manajer yang baik sehingga membuat karyawan merasa nyaman dan karyawan merasa diapresiasi oleh atasannya. Selain itu, employee engagement juga memiliki pengaruh terhadap kepuasan kerja sehingga employee engagement dapat memediasi hubungan antara FSSB dan kepuasan kerja. Penelitian oleh Radosevich, et al. (2008) secara konsisten menyimpulkan bahwa employee engagement dapat berfungsi sebagai penentu utama kepuasan kerja. Radosevich, et al. (2008) berpendapat bahwa karyawan yang engaged memiliki kepuasan kerja yang lebih tinggi, jika dibandingkan dengan karyawan yang tidak engaged. Temuan dalam penelitian ini menunjukkan bahwa FSSB dapat mendorong timbulnya employee engagement pada perawat RSUD Dr. Saiful Anwar. Berdasarkan social exchange theory, karyawan akan memberikan kontribusi sesuai dengan apa yang mereka dapatkan, dalam hal ini adalah FSSB. Temuan dalam penelitian ini menunjukkan bahwa perawat pada RSUD Dr. Saiful Anwar Malang memiliki employee engagement yang baik. Hasil penelitian ini menunjukkan employee engagement yang baik terbentuk sebagai dampak dari perlakuan baik dan perhatian dari supervisor mereka. Temuan dalam penelitian ini membuktikan bahwa FSSB dapat mendorong timbulnya employee engagement, sehingga RSUD Dr. Saiful Anwar Malang memerlukan supervisor yang support agar dapat menciptakan employee engagement dan kemudian dapat meningkatkan kepuasan kerja pada perawatnya.

Hasil penelitian dalam penelitian ini menemukan bahwa WLB pada perawat memiliki nilai yang cenderung rendah. Hal ini salah satunya disebabkan 
oleh workload pada RSUD Dr. Saiful Anwar Malang. Menurut Eby, et al. (2005) rendahnya tingkat work life balance dapat dipengaruhi oleh beban kerja yang tinggi. Keterbatasan dalam penelitian ini adalah tidak menyertakan workload sebagai variabel yang diteliti.

\section{SIMPULAN DAN SARAN}

Hasil analisis dan pembahasan pada penelitian ini secara keseluruhan menunjukkan bahwa Family Supportive Supervisor Behaviour berpengaruh secara signifikan terhadap Kepuasan Kerja dan Employee Engagement, namun Family Supportive Supervisor Behaviour berpengaruh tidak signifikan terhadap Work Life Balance. Employee Engagement berpengaruh secara signifikan terhadap Kepuasan Kerja, namun Work Life Balance berpengaruh secara tidak signifikan terhadap Kepuasan Kerja. Selanjutnya, Employee Engagement memediasi pengaruh Family Supportive Supervisor Behaviour terhadap Kepuasan Kerja.

Berdasarkan hasil penelitian ini maka saran yang dapat diberikan pada RSUD Dr. Saiful Anwar Malang adalah agar memberikan pembinaan kepada supervisor untuk lebih dapat meluangkan waktu untuk mengetahui kebutuhan pribadi perawat. Selain itu, FSSB dalam penelitian ini ditemukan berpengaruh signifikan terhadap employee engagement dan kepuasan kerja sehingga penting bagi RSUD Dr. Saiful Anwar Malang untuk meningkatkan kemampuan supervisor dalam memberikan dukungan kepada bawahan dengan cara mengadakan pelatihan agar dapat meningkatkan employee engagement dan kepuasan kerja.

Saran untuk penelitian selanjutnya, agar melakukan penelitian serupa namun dengan sektor yang berbeda dan dengan jumlah sampel yang lebih beragam sehingga mampu memperkuat hasil penelitian-penelitian yang telah dilakukan sebelumnya. Penelitian selanjutnya dapat menggunakan variabel workload yang tidak diteliti dalam penelitian ini, kaitannya dengan WLB. Penelitian selanjutnya juga diharapkan menggunakan variabel lain yang mempengaruhi FSSB agar mendapatkan hasil temuan yang lebih beragam lagi.

\section{REFERENSI}

Abigail, D., \& Johnson, B. (2014). The Effects of Family Supportive Supervisor Behaviors
(FSSB) on Work and Health Related Outcomes. (January).

Afrianty, T. W. (2013). Work Life Balance Policies in the Indonesian Context (Curtin University). Retrieved from https://espace.curtin.edu.au/ bitstream/handle/20.500.11937/82/ 199554_Afrianty 2014.pdf

Allan, L. L., Lu, C. C., Gursoy, D., \& Neale, N. R. (2016). Work engagement, job satisfaction, and turnover intentions: a comparison between supervisors and line-level employees. International Journal of Contemporary Hospitality Management, 28(4).

Aryee, S., Srinivas, E. S., \& Tan, H. H. (2005). Rhythms of life: Antecedents and outcomes of work-family balance in employed parents. Journal of Applied Psychology, 90(1), 132146. https://doi.org/10.1037/0021-9010.90.1.132

Bakker, A. B., \& Demerouti, E. (2007). The Job Demands-Resources model: State of the art. Journal of Managerial Psychology, 22(3), 309-328. https://doi.org/10.1108/02683940710 733115

Baral, R., \& Bhargava, S. (2010). Work family enrichment as a mediator between organizational interventions for work life balance and job outcomes. Journal of Managerial Psychology, 25(3), 274-300. https://doi.org/10.1108/ 02683941011023749

Bohle, P., \& Tilley, A. J. (1998). Early experience of shiftwork: Influences on attitudes. Journal of Occupational and Organizational Psychology, 71(1), 61-79. https://doi.org/ 10.1111/j.2044-8325.1998.tb00663.x

Brough, P., O'Driscoll, M. P., \& Kalliath, T. J. (2005). The ability of "family friendly" organizational resources to predict work-family conflict and job and family satisfaction. Stress and Health, 21(4), 223-234. https://doi.org/ 10.1002/smi.1059

Casper, W. J., Harris, C., Taylor-Bianco, A., \& Wayne, J. H. (2011). Work-family conflict, perceived supervisor support and organizational commitment among Brazilian professionals. Journal of Vocational Behavior, 79(3), 640652. https://doi.org/10.1016/j.jvb.2011.04.011

Choi, J. (2008). Work and family demands and life stress among Chinese employees: The mediating effect of work-family conflict. International Journal of Human Resource 
Management, 19(5), 878-895. https://doi.org/ 10.1080/09585190801993885

Clark, S. C. (2000). Work/Family Border Theory: A New Theory of Work/Family Balance. Human Relations.

Closon, C., Leys, C., \& Hellemans, C. (2015). Perceptions of corporate social responsibility, organizational commitment and job satisfaction. Management Research, 13(1), 31-54. https:// doi.org/10.1108/MRJIAM-09-2014-0565

Colquhoun, W. P. (1981). Shift Work/ : Discussion and Conclusion. Washington.

Crawford, E. R., LePine, J. A., \& Rich, B. L. (2010). Linking job demands and resources to employee engagement and burnout: A theoretical extension and meta-analytic test. Journal of Applied Psychology, 95(5), 834-848. https:// doi.org/10.1037/a0019364

Eby, L. T., Casper, W. J., Lockwood, A., Bordeaux, C., \& Brinley, A. (2005). Work and family research in IO/OB: Content analysis and review of the literature (1980-2002). Journal of Vocational Behavior, 66(1), 124-197. https:// doi.org/10.1016/j.jvb.2003.11.003

Eisenberger, R., Huntington, R., Hutchison, S., \& Sowa, D. (1986). Perceived Organizational Support. Journal of Applied Psychology, 500507.

Haar, J. M., Russo, M., Suñe, A., \& Ollier-Malaterre, A. (2014). Outcomes of work-life balance on job satisfaction, life satisfaction and mental health: A study across seven cultures. Journal of Vocational Behavior, 85(3), 361-373. https://doi.org/10.1016/j.jvb.2014.08.010

Hammer, L. B., Kossek, E. E., Yragui, N. L., Bodner, T. E., \& Hanson, G. C. (2011). Development and Validation of a Multidimensional Measure of Family Supportive Supervisor Behaviors (FSSB). Journal of Management, 71(2), 233-236. https://doi.org/ 10.1038/mp.2011.182.doi

Hammer, L. B., Kossek, E. E., Zimmerman, K., \& Daniels, R. (2007). Exploring the work and nonwork interface. Research in Occupational Stress and Well Being, 6, 165-204.

Handayani. (2013). Keseimbangan Kerja Keluarga pada Perempuan Bekerja: Tinjauan Teori Border. Buletin Psikologi, 21(2), 90-101.

Hassan, Z., Dollard, M. F., \& Winefield, A. H. (2010). Work-family conflict in East vs western countries. Cross Cultural Management, 17(1),
30-49. https://doi.org/10.1108/135276010110 16899

Hayman, J. (2005). Psychometric Assessment of an Instrument Designed to Measure Work Life Balance. American Educational Research Journal, 5(2), 285-285. https://doi.org/10.3102/ 00028312005002285

Hudson. (2005). The Case for Work / Life Balance. 1-39.

Ibrahim, M., \& Al Falasi, S. (2014). Employee loyalty and engagement in uae public sector. Employee Relations, 36(5), 562-582. https://doi.org/ 10.1108/ER-07-2013-0098

Koller, M. (2004). Health risks related to shift work. International Archives of Occupational and Environmental Health, 53(1), 59-75. https:// doi.org/10.1007/bf00406178

Mas-Machuca, M., Berbegal-Mirabent, J., \& Alegre, I. (2016). Work-life balance and its relationship with organizational pride and job satisfaction. Journal of Managerial Psychology, 31(2), 586-602. https://doi.org/ 10.1108/JMP-09-2014-0272

Munn, E. K., Barber, C. E., \& Fritz, J. J. (1996). Children's Health Care Mitral Value Prolapse and Symptoms of Negative Affectivity in Adolescents. Children'S Health Care, 25(2), 37-41. https://doi.org/10.1207/s15326888 chc 2502

Radosevich, D.J., Radosevich, D.M., Riddle, M.R. \& Huges, P. A. (2008). Goal Orientation as a Predictor of Cognitive Engagement, Performance and Satisfaction. Journal of the Academy of Business and Economics, 8(3), 46-55.

Ramos, A. O., \& Almeida, H. de. (2017). Work engagement, social support, and job satisfaction in Portuguese nursing staff: A winning combination. Applied Nursing Research, 36, 37-41. https://doi.org/10.1016/j.apnr.2017.05 .012

Republik Indonesia. (2013). Peraturan Menteri Tenaga Kerja No. 233 Tahun 2003 Tentang Jenis-Jenis Pekerjaan. Jakarta.

Rhoades, L., \& Eisenberger, R. (2002). Perceived organizational support: A review of the literature. Journal of Applied Psychology, 87(4), 698-714. https://doi.org/10.1037/00219010.87.4.698

Robbins, S., \& Judge, T. (2013). Organizational Behaviour. England: Pearson Education Limited. 
Saks, A. M. (2005). Antecedents and consequences of employee engagement revisited. Journal of Organizational Effectiveness, 6(1), 19-38. https://doi.org/10.1108/JOEPP-06-2018-0034

Schaufeli, W. B., Salanova, M., \& Bakker, V. G. 'Alez-R. 'A A. B. (2002). The Measurement Of Engagement And Burnout: A Two Sample Confirmatory Factor Analytic Approach (Received. Journal of Happiness Studies, 3(71), 60. Retrieved from https://de.statista.com .bibproxy.fh-kufstein.ac.at/statistik/daten/ studie/708566/umfrage/einfluss-voninfluencern-auf-kaufentscheidung-nach-alterin-deutschland/
Sutrisno, E. (2014). Manajemen Sumber Daya Manusia (Edisi 1). Jakarta: Kencana.

Worth, T. (2011). Careers With High Rates of Depression. Health.Com. Retrieved from http:/ /www.health.com/health/gallery/0,,20428990, 00.html

Yeh, C. M. (2013). Tourism involvement, work engagement and job satisfaction among frontline hotel employees. Annals of Tourism Research, 42(xx), 214-239. https://doi.org/10.1016/ j.annals.2013.02.002 